\section{AB0511 A COMPARATIVE STUDY ON CLINICAL AND SEROLOGICAL CHARACTERISTICS BETWEEN PATIENTS WITH RHUPUS AND PATIENTS WITH SYSTEMIC LUPUS ERYTHEMATOSUS}

Beatriz Frade Sosa ${ }^{1}$, J. Narváez ${ }^{2}$, Tarek Carlos Salman Monte ${ }^{3}$, Vera Ortiz Santamaría ${ }^{4}$, Vicenç Torrente Segarra ${ }^{5}$, Ivan Castellvi ${ }^{6}$, Berta Magallares ${ }^{6}$, Raul Castellanos-Moreira ${ }^{1}$, Delia Reina ${ }^{7}$,Sonia Mínguez ${ }^{8}$, Maria Garcia Manrique de Lara ${ }^{9}$, Sergi Ordoñez ${ }^{10}$, Meritxell Sallés Lizarzaburu ${ }^{8}$, Elena Riera Alonso ${ }^{11}$, Jose A. Gómez-Puerta ${ }^{1}{ }^{1}$ Hospital Clinic Barcelona, Rheumatology, Barcelona, Spain; ${ }^{2}$ Hospital de Bellvitge, Rheumatology, L'Hospitalet de Llobregat, Spain; ${ }^{3}$ Hospital del Mar, Rheumatology, Barcelona, Spain; ${ }^{4}$ Hospital General de Granollers, Rheumatology, Granollers, Spain; ${ }^{5}$ Hospital Comarcal de l'Alt Penedès, Rheumatology, Barcelona, Spain; ${ }^{6} \mathrm{Hospital}$ Santa Creu i Sant Pau, Rheumatology, Barcelona, Spain; ${ }^{7}$ Hospital Sant Joan Despí Moisès Broggi, Rheumatology, Barcelona, Spain; ${ }^{8}$ Althaia, Xarxa Assistencial Universitària de Manresa, Rheumatology, Manresa, Spain; ${ }^{9}$ Hospital Parc Taulí, Rheumatology, Sabadell, Spain; ${ }^{10}$ Hospital Arnau de Vilanova, Rheumatology, Lleida, Spain; ${ }^{11}$ Hospital Mutua de Terrasa, Rheumatology, Terrasa, Spain

Background: Concomitant presence of two autoimmune diseases, such as rheumatoid arthritis (RA) and systemic lupus erythematosus (SLE) is known as "Rhupus". Although poliautoimmunity is not uncommon phenomenon, only a small series of patients have been described so far with Rhupus.

Objectives: Our purpose was to analyze the clinical and serological characteristics of patients with Rhupus and compare them with a cohort of patients with SLE.

Methods: In this cross-sectional study, we included cases of Rhupus (ACR/EULAR 2010 plus ACR 1987 criteria) from 11 different Rheumatology Departments at Catalonia, Spain. We included patients with a diagnosis of SLE in a 2:1 ratio matched by sex, race and disease duration. To avoid misclassification, those patients with Rhupus but who had Jaccoud's arthropathy or with overlap syndromes were excluded.

Results: A total of 120 patients were included, 40 cases with Rhupus and 80 cases with SLE. Most of patients were female (95\%) and Caucasian $(75 \%)$. Mean age was $51.0 \pm 14.7$ years with a mean disease duration of $12.9 \pm 9.2$ years. Main clinical characteristics were articular involvement $(93.3 \%)$, cutaneous involvement $(77.5 \%)$, haematological (72.5\%), secondary Sjögren syndrome (38.7\%) among others. Clinical and serological characteristics according different groups are shown in Table.

\begin{tabular}{|c|c|c|c|}
\hline & $\begin{array}{c}\text { Total } \\
\mathrm{N}=120\end{array}$ & $\begin{array}{c}\text { Rhupus } \\
\mathrm{n}=40\end{array}$ & $\begin{array}{c}\text { SLE } \\
\mathrm{n}=80\end{array}$ \\
\hline Gender (Female),\% & $114(95 \%)$ & $38(95 \%)$ & $76(95 \%) 1$ \\
\hline Mean age, years \pm SD & $51,0 \pm 14,7$ & $57,10 \pm 14,1^{\S}$ & $47,9 \pm 14,2$ \\
\hline Disease duration, years $\pm S D$ & $12,9 \pm 9,2$ & $13,6 \pm 7,9$ & $12,6 \pm 9,8$ \\
\hline Race (Caucasian),\% & $84(75 \%)$ & $25(78,1 \%)$ & $59(73,8 \%)$ \\
\hline \multicolumn{4}{|l|}{ Clinical characteristics } \\
\hline Cutaneous involvement,\% & $93(77,5 \%)$ & $31(77,5 \%)$ & $62(77,5 \%)$ \\
\hline Articular involvement,\% & $112(93,3 \%)$ & $40(100 \%)^{\S}$ & $72(90,0 \%)$ \\
\hline - Arthritis,\% & $96(80,0 \%)$ & $40(100 \%) \S \S$ & $56(70,0 \%)$ \\
\hline - Erosive disease,\% & $25(20,8 \%)$ & $24(60,0 \%) \S \S$ & $1(1,3 \%)$ \\
\hline - Tenosynovitis,\% & $37(30,8 \%)$ & $22(55,0 \%) \S \S$ & $15(18,8 \%)$ \\
\hline Renal involvement,\% & $24(10 \%)$ & $4(10,0 \%)^{\S}$ & $20(25,0 \%)$ \\
\hline Mean SLEDAI * & $2,9 \pm 2,8$ & $2,6 \pm 2,5$ & $3,0 \pm 3,0$ \\
\hline \multicolumn{4}{|l|}{ Immunological features } \\
\hline Positive RF,\% & $37(32,7 \%)$ & $32(80 \%) \S \S$ & $6(6,8 \%)$ \\
\hline Positive anti-CCP,\% & $33(30,6 \%)$ & $31(81,6 \%) \S \S$ & $2(2,9 \%)$ \\
\hline Comorbidity $¥$ & $44(36,7 \%)$ & $20(50,0 \%)^{\S}$ & $24(30,0 \%)$ \\
\hline SLICC * & $0,8 \pm 1,36$ & $1,3 \pm 1,55 \S \S$ & $0,6 \pm 1,2$ \\
\hline \multicolumn{4}{|l|}{ Treatment (ever) } \\
\hline Prednisolone, $\%$ & $100(84,7 \%)$ & $39(97,5 \%) \S \S$ & $61(78,2 \%)$ \\
\hline Antimalarial & $109(91,6 \%)$ & $35(89,7 \%)$ & $74(92,5 \%)$ \\
\hline MTX\% & $58(48,7 \%)$ & $33(82,5 \%)^{\S \S}$ & $25(31,6 \%)$ \\
\hline Rituximab,\% & $24(20,2 \%)$ & $13(33,3 \%)^{\S}$ & $11(13,8 \%)$ \\
\hline
\end{tabular}

* Last visit, ${ }^{*}$ Comorbidities included: Hypertension, DM, dyslipemia, osteoporosis or Cushing.

Conclusion: We found some clinical and serological differences among patients with Rhupus vs SLE alone. As expected, articular domains and positive RF and ACPAs were higher in Rhupus. By other hand, renal involvement was more common among "pure" SLE patients. Rhupus patients were more commonly treated with prednisolone, MTX and rituximab, and had more comorbidities and organ damage. If Rhupus represent a different condition, requires further analysis in bigger cohorts.

Disclosure of Interests: Beatriz Frade Sosa: None declared, J. Narváez Consultant for: Bristol-Myers Squibb, Tarek Carlos Salman Monte: None declared, Vera Ortiz Santamaría: None declared, Vicenç Torrente Segarra None declared, Ivan Castellví Consultant for: I received fees less than 5000USD as a consultant for Kern and Actelion, Paid instructor for: received fees less than 2000USD as a instructor for Boehringer -Ingelheim, Novartis and Gebro, Speakers bureau: ND, Berta Magallares: None declared, Raul Castellanos-Moreira Speakers bureau: MSD, Lilly, Delia Reina Speakers bureau: MSD, Novartis, Pfizer, Janssen, Sonia Mínguez: None declared, Maria Garcia Manrique de Lara: None declared, Sergi Ordoñez : None declared, Meritxell Sallés Lizarzaburu: None declared, Elena Riera Alonso: None declared, Jose A. Gómez-Puerta Consultant for: Pfizer, Roche, Speakers bureau: Abbvie, BMS, Janssen, MSD, Pfizer, Roche

DOI: 10.1136/annrheumdis-2019-eular.7121

\section{AB0512 ANTI-CARBAMYLATED PROTEIN ANTIBODIES IN SYSTEMIC LUPUS ERYTHEMATOSUS: ARE THEY USEFUL?}

Rajesh Kumar ${ }^{1}$, llaria Cavazzana ${ }^{1}$, Micaela Fredi ${ }^{1,2}$, Roberta Ottaviani ${ }^{2}$, Angela Tincani ${ }^{1}, 2$, Franco Franceschini ${ }^{1}, 2 .{ }^{1}$ Rheumatology and Clinical Immunology Unit, ASST Spedali Civili Brescia, Brescia, Italy; ${ }^{2}$ Department of Clinical and Experimental Sciences, University of Brescia, Brescia, Italy

Background: Anti-carbamylated protein antibodies (anti-CarP) have been described not only in Rheumatoid arthritis but in other systemic autoimmune diseases. Recently, they have been reported in different cohorts of Systemic Lupus Erythematosus (SLE) with a prevalence of 9-28\% (1-4). Anti-CarP have been proposed as a marker of erosive arthitis in SLE(4). Objectives: The aim of this work was to assess the prevalence of antiCarP in SLE patients from a single center cohort and their association to clinical and laboratory data.

Methods: Anti-CarP were evaluated using a home-made ELISA (5), with some modifications: all the incubations has been reduced to $1.5 \mathrm{hrs}$ at room temperature and the reaction was developed with diethanolamine and read at $405 \mathrm{~nm}$. The cut-off value of 0.350 optical density (OD) was set up, testing 230 healthy controls sera, calculating the average plus 3 times standard deviation. The ROC curve analysis demonstrated a specificity and sensitivity of 0,98 and 0,32 , respectively. The OD was converted to arbitrary units (AU) with $20 \mathrm{AU}$ as cut-off value. Clinical data were obtained from clinical charts.

Results: Anti-CarP antibodies were found in 80/282 (28,3\%) SLE patients Complete clinical and serological data were available for 217 patients (76,9\%): 71 positive and 146 negative. No clinical associations were found with anti-CarP antibodies. However, cytopenia and renal involvement were more frequently assessed in patients without anti-CarP antibodies ( $\mathrm{p}$ : 0,019 ; OR 0,$49 ; 95 \% \mathrm{Cl} \quad 0,26-0,91$ and $\mathrm{p}: 0,07$, respectively). Among the patients evaluated, 56 were treated with anti-Blys therapy (belimumab). In this subgroup, sera collected at the first administration (T0), after 6 months (T6) and after 12 months (T12) were tested. At baseline anti-CarP were positive in $10(17,8 \%)$ with a mean titre of 37 AU (SD: 17,9). AntiCarp titre significantly decreased at T6 (p: 0.006) and T12 (p. 0.01). Negative seroconversion was observed in 7/10 sera.

Conclusion: the prevalence of anti-CarP antibodies found in our cohort is in line with to what previously reported. In our hands, anti-CarP antibodies are not associated to any clinical SLE features.

\section{REFERENCES}

[1] Ziegelasch M, et al. Arthritis Res and Ther 2016; 18: 289.

[2] Nakabo S, et al. J Rheumatol 2017 Sep;44(9):1384-1388.

[3] Pecani A, et al. Arthritis Res Ther 2016 Nov 25;18(1):276.

[4] Ceccarelli F, et al. Arthritis Res Ther 2018 Jun 14;20(1):126.

[5] Shi J, et al. Proceedings of the National Academy of Sciences of the United States of America. 2011;108(42):17372-7.

Disclosure of Interests: Rajesh Kumar : None declared, Ilaria Cavazzana: None declared, Micaela Fredi: None declared, Roberta Ottaviani: None declared, Angela Tincani Consultant for: UCB, Pfizer, Abbvie, BMS, Sanofi, Roche, GSK, AlphaSigma, Lilly, Jannsen, Cellgene, Novartis, Franco Franceschini: None declared DOI: 10.1136/annrheumdis-2019-eular.6966 